\title{
Twin Reversed Arterial Perfusion(TRAP) Sequence; Characteristic Gray-Scale and Doppler Ultrasonography Findings
}

\author{
Ayla Buyukkaya ${ }^{1, *}$; Guven Tekbas ${ }^{2}$; Ramazan Buyukkaya ${ }^{3}$ \\ ${ }_{1}^{1}$ Department of Radiology, Duzce Ataturk Government Hospital, Duzce, Turkey \\ 2 Department of Radiology, School of Medicine, Dicle University, Diyarbakır, Turkey \\ 3 Department of Radiology, School of Medicine, Duzce University, Duzce, Turkey \\ ${ }^{*}$ Corresponding author: Ayla Buyukkaya, Department of Radiology, Duzce Ataturk Government Hospital, Duzce, Turkey. Tel: +90-3805421390, Fax: +90-3805421387, E-mail: rabuyuk-
} kaya@gmail.com

Received: September 22, 2013; Accepted: February 1, 2014

\begin{abstract}
Twin reversed arterial perfusion (TRAP) sequence is a syndrome with poor prognosis, seen only in monochorionic monozygotic twin pregnancies. The incidence is one in 35.000 births and one in 100 monozygotic twin pregnancies. It is characterized with a recipient fetus exhibiting lethal anomalies including acardia and a pump fetus. Mortality is usually due to heart failure or premature labor caused by polyhydramnios of pump fetus. Herein, we report a case of TRAP sequence that emphasizes the importance of gray-scale and color Doppler imaging in the diagnosis and management of TRAP sequence.

Keywords: Ultrasound; Pregnancy; Twin
\end{abstract}

\section{Introduction}

Twin reversed arterial perfusion (TRAP) sequence is a phenomenon with poor prognosis which is seen in 1/100 of monochorionic twin pregnancies. In TRAP sequence, there is a non-viable, acardiac fetus that has multiple anomalies and a pump fetus that feeds this fetus via vascular anastomosis in the placenta. Its incidence is 1 in 35,000 among all deliveries and one in 100 in monochorionic twin pregnancies (1). While the pump twin is anatomically normal, development is limited in only the lower part of the body in the acardiac twin of which the blood supply is provided from hypoxic blood, as in our case. Mortality is $100 \%$ in acardiac twin. Mortality of pump twin is around $50 \%$ and death is usually due to heart failure and sometimes prematurity caused by polyhydramnios (2). Herein, we present ultrasonography and Doppler findings of our TRAP case under the light of literature.

\section{Case Presentation}

A 21-year-old pregnant woman with 23 weeks of gestational age was referred to our clinic for advanced ultrasonography and Doppler examination with prediagnosis of fetal anomaly. Her medical history and family history were unproblematic and she did not have any systemic diseases. On obstetric ultrasonography, she had an intrauterine monochorionic monoamniotic twin pregnancy (Figure 1). Cardiac activity was rhythmic in the first fetus and fetal heart rate was 149 beat per minute and morphometric measurements were consistent with 23 weeks and 4 days, and no anomalies were detected. Fetal cardiac ac- tivity was not detected in the rudimentary thorax of the second fetus. Biparietal diameter and head circumference measurements could not be done as the fetal cranium could not be observed. The fetal abdomen was surrounded with a large hydrops ring and the lengths of the extremities were consistent with 20 weeks and 2 days (Figure 2). Umbilical circulation occurred through reversed perfusion in the recipient twin. On Doppler USG, umbilical artery systolic/diastolic (S/D) ratio increased in the pump twin and within normal ranges in the recipient twin (Figure 3). Under the light of these data, twin-twin transfusion syndrome and TRAP sequence were considered in the radiologic differential diagnosis of this complicated

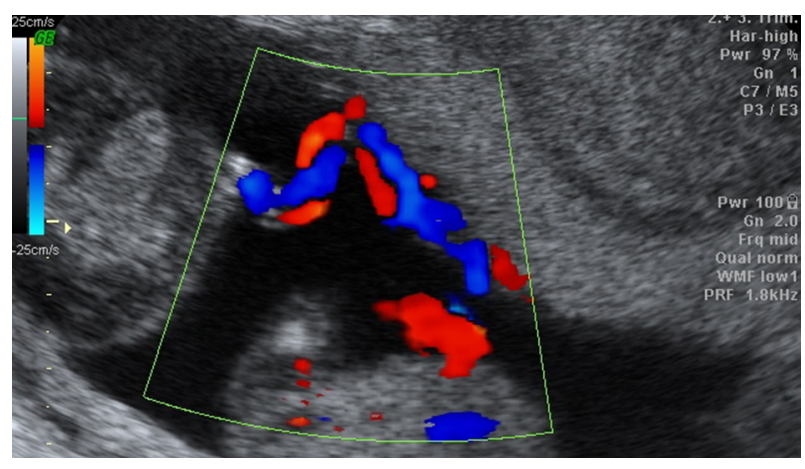

Figure 1. Twin fetuses in a 21-year-old pregnant woman with 23 weeks of gestational age and a prediagnosis of fetal anomaly. Ultrasound images in two different twins showing excessive growth of the acardiac twin compared to the pump twin.

Copyright (C) 2015, Tehran University of Medical Sciences and Iranian Society of Radiology. This is an open-access article distributed under the terms of the Creative Commons Attribution-NonCommercial 4.0 International License (http://creativecommons.org/licenses/by-nc/4.0/) which permits copy and redistribute the material just in noncommercial usages, provided the original work is properly cited. 

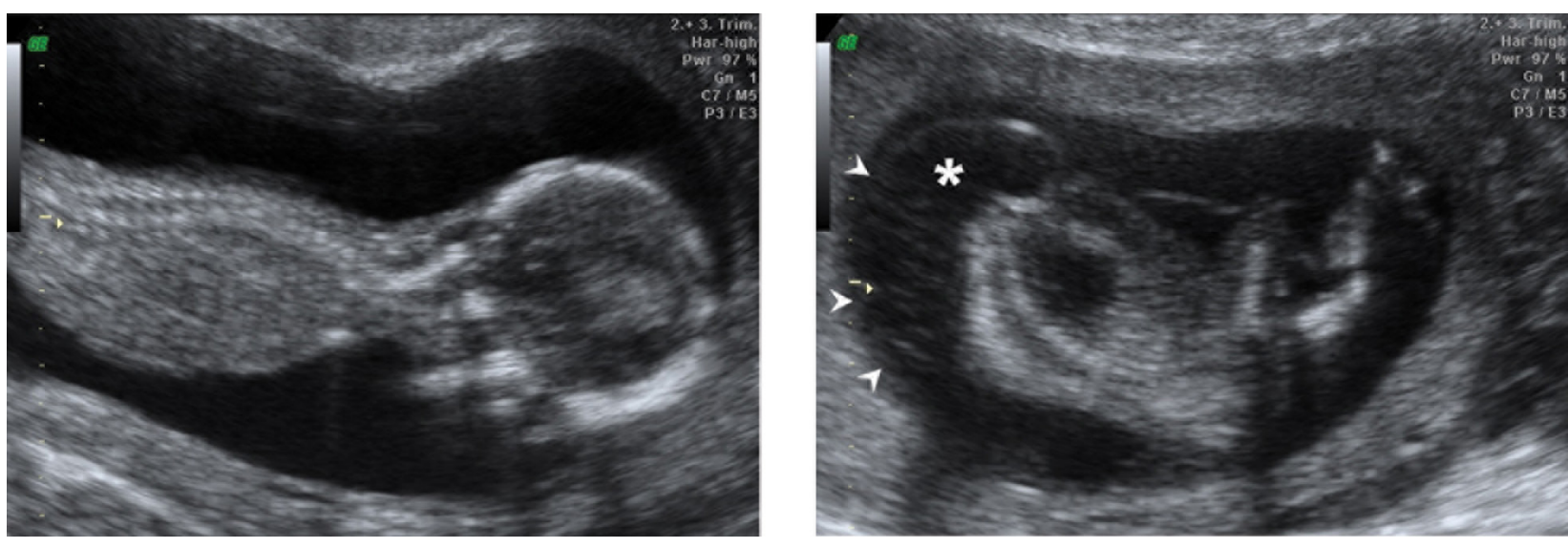

Figure 2. Sonogram of recipient twin demonstrates well-developed lower limbs, partially developed abdomen and thorax, absent head and upper limbs $(*)$, and diffuse soft tissue edema (arrowheads)
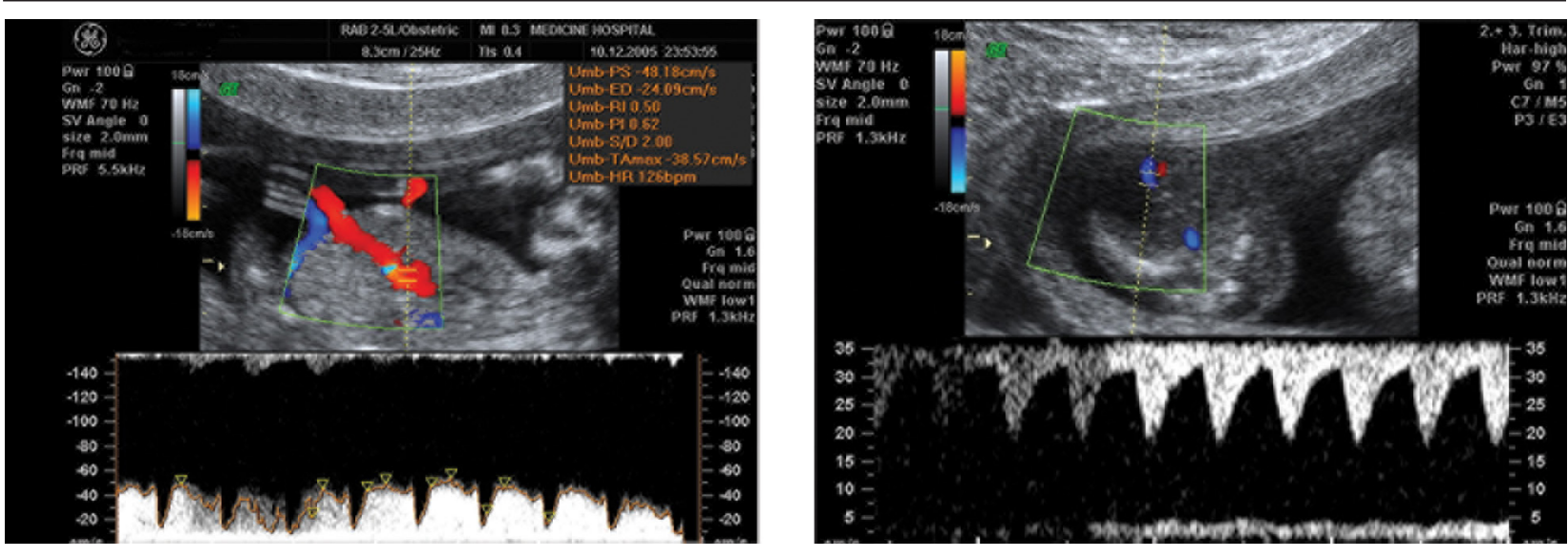

Figure 3. Pulsed Doppler sonographic image of perfused twin demonstrates reversal of flow in the umbilical artery. Umbilical artery S/D ratio is increased in the pump twin and is within normal range in the recipient twin

monochorionic-monoamniotic twin pregnancy. Chorionicity, presence of hydropic, acardiac and acephalic twin and Doppler USG findings were consistent with TRAP sequence.

\section{Discussion}

TRAP sequence represents a variant of conjoint twins in which chorionic circulation is shared (3). Organogenesis defect due to anastomosis in the placenta during the early embryonic period is suggested in the pathogenesis of TRAP sequence (1). In acardiac fetus placenta blood circulation between acardiac fetus and donor fetus is provided by artery-artery and vein-vein anastomosis on the placental surface $(2,4)$. The acardiac twin survives through these anastomoses, it uses blood which has poor oxygen, coming from cardiac twin flows reversely in arteries of the acardiac fetus and normal tissues of this fetus are partially atrophic. Atrophy is higher in the cranial parts as the caudal part uses blood predominantly (5).

Antenatal diagnosis may be made by absence of the heart on ultrasonography and revealing placental vascu- lar anastomosis with Doppler despite presence of trunk and extremity movements in the twin that has multiple anomalies (6). Prenatal diagnosis of acardiac fetus may be made with ultrasonography at the end of the first trimester (3). Doppler studies may show pathognomonic features of reverse flow on artery-artery anastomosis (1).

Acardiac fetus is clinically divided into two types. Pseudocardiac is the presence of cardiac structures although rudimentary. Halocardia is the absence of cardiac structure development. It is widely classified into four subgroups morphologically $(4,7)$.

1. Acardiac acephalic: the fetus has developed pelvis and lower extremities. Head, arms and thoracic organs are absent. This is the most common type with a frequency of $60-75 \%$. Our case is in this group.

2. Acardiac anceps: body and extremities have developed. Head and face are partially formed. This type consists approximately $20 \%$ of all cases.

3. Acardiac acormus: only the head of the fetus has developed. It is quite rare and consists approximately $10 \%$ of all cases. 
4. Acardiac amorphous: the fetus has no identifiable organs. It is as an amorphous tissue mass and it consists approximately $5 \%$ of all cases.

Mortality is $100 \%$ for acardiac twin. Mortality of pump twin is around $50 \%$ and death may usually be due to heart failure and sometimes prematurity caused by polyhydramnios (5). Chromosomal anomalies that are reported as $9 \%$ should be excluded for management of TRAP sequence. Significance of early diagnosis is clear both for determining the therapy and also timely terminating the pregnancy which has a high mortality (2). One of the prognostic factors is the ratio of the weight of the acardiac twin to the weight of the donor twin (\%). Preterm delivery is seen in $90 \%$, polyhydramnios in $40 \%$, and congestive heart failure in 30\% when this ratio is above $70 \%$ (5). However, it is quite difficult to estimate the weight of the acardiac twin. Continuance of the growth of the acardiac twin, presence of polyhydramnios, cardiomegaly and pericardial effusion are poor prognostic factors. On color Doppler ultrasonography, low pulsatility index in the umbilical artery of the donor twin indicates poor prognosis (8).

Optimal management of acardiac twin pregnancy is controversial as it is seen rarely and with different variations. The goal of therapy is the salvage of the pump twin. Fetal and neonatal mortality rate of pump twin is high. Therefore, invasive methods toward eliminating the acardiac twin are selected (9). Discontinuation of the blood flow to the acardiac twin is the method that is applied by many authors. These methods include endoscopic umbilical cord ligation (10), sclerosis of the umbilical cord with alcohol (11), thermocoagulation of the umbilical cord and aorta under ultrasonography guidance (12), and coagulation of the umbilical cord $(13,14)$.

Sullivan et al. evaluated the patients with weekly serial ultrasonographies, fetal echocardiography, Doppler flow assessment, non-stress test and biophysical profile. They suggested that conservative follow-up methods have a lower mortality compared to invasive methods (15).

In conclusion, TRAP sequence is a complication that is seen in monochorionic twin pregnancies and it has a poor prognosis. Selection of the proper treatment modality by making the diagnosis with typical ultrasonography and Doppler findings is of great importance.

\section{Authors' Contributions}

Ayla Buyukkaya is the corresponding author who wrote the manuscript. Guven Tekbas first saw the cases. Ramazan Buyukkaya was responsible for English grammar checking and literature data research.

\section{References}

1. Hecher K, Ville Y, Nicolaides KH. Color Doppler ultrasonography in the identification of communicating vessels in twin-twin transfusion syndrome and acardiac twins. J Ultrasound Med. 1995;14(1):37-40.

2. Van Allen MI, Smith DW, Shepard TH. Twin reversed arterial perfusion (TRAP) sequence: a study of 14 twin pregnancies with acardius. Semin Perinatol.1983;7(4):285-93.

3. Langlotz H, Sauerbrei E, Murray S. Transvaginal Doppler sonographic diagnosis of an acardiac twin at 12 weeks gestation. $J$ Ultrasound Med.1991;10(3):175-9.

4. Wong AE, Sepulveda W. Acardiac anomaly: current issues in prenatal assessment and treatment. Prenat Diagn. 2005;25(9):796-806.

5. Moore TR, Gale S, Benirschke K. Perinatal outcome of forty-nine pregnancies complicated by acardiac twinning. Am J Obstet Gynecol.1990;163(3):907-12.

6. Schwarzler P, Ville Y, Moscosco G, Tennstedt C, Bollmann R, Chaoui R. Diagnosis of twin reversed arterial perfusion sequence in the first trimester by transvaginal color Doppler ultrasound. $U l$ trasound Obstet Gynecol.1999;13(2):143-6.

7. Hartge DR, Weichert J. Prenatal diagnosis and outcome of multiple pregnancies with reversed arterial perfusion (TRAP-sequence). Arch Gynecol Obstet. 2012;286(1):81-8.

8. Dashe JS, Fernandez CO, Twickler DM. Utility of Doppler velocimetry in predicting outcome in twin reversed-arterial perfusion sequence. Am J Obstet Gynecol. 2001;185(1):135-9.

9. Robie GF, Payne GJ, Morgan MA. Selective delivery of an acardiac, acephalic twin. NEngl J Med.1989;320(8):512-3.

10. McCurdy CJ, Childers JM, Seeds JW. Ligation of the umbilical cord of an acardiac-acephalus twin with an endoscopic intrauterine technique. Obstet Gynecol.1993;82(4 Pt 2 Suppl):708-11.

11. Corbacioglu A, Gul A, Bakirci IT, Gedikbasi A, Yildirim G. Treatment of twin reversed arterial perfusion sequence with alcohol ablation or bipolar cord coagulation. Int J Gynaecol Obstet. 2012;117(3):257-9.

12. Rodeck C, Deans A, Jauniaux E. Thermocoagulation for the early treatment of pregnancy with an acardiac twin. $N$ Engl J Med. 1998;339(18):1293-5.

13. Deprest JA, Audibert F, Van Schoubroeck D, Hecher K, MahieuCaputo D. Bipolar coagulation of the umbilical cord in complicated monochorionic twin pregnancy. Am J Obstet Gynecol. 2000;182(2):340-5.

14. Berg C, Holst D, Mallmann MR, Gottschalk I, Gembruch U, Geipel A. Early vs late intervention in twin reversed arterial perfusion sequence. Ultrasound Obstet Gynecol. 2014;43(1):60-4.

15. Sullivan AE, Varner MW, Ball RH, Jackson M, Silver RM. The management of acardiac twins: a conservative approach. Am J Obstet Gynecol. 2003;189(5):1310-3. 